\title{
Time to Refocus Assessment of Vision in Older Adults? Contrast Sensitivity but Not Visual Acuity Is Associated With Gait in Older Adults
}

James Loughman

Technological University Dublin, james.loughman@tudublin.ie

Eoin Duggan

Trinity College Dublin, Ireland

Orna Donoghue,

Trinity College Dublin, Ireland

See next page for additional authors

Follow this and additional works at: https://arrow.tudublin.ie/otpomart

Part of the Optometry Commons

\section{Recommended Citation}

Duggan E. et al. (2017) Time to Refocus Assessment of Vision in Older Adults? Contrast Sensitivity but Not Visual Acuity Is Associated With Gait in Older Adults. J Gerontol A Biol Sci Med Sci, 2017, Online First. doi:10.1093/gerona/glx021

This Article is brought to you for free and open access by ARROW@TU Dublin. It has been accepted for inclusion in Articles by an authorized administrator of ARROW@TU Dublin. For more information, please contact arrow.admin@tudublin.ie, aisling.coyne@tudublin.ie, gerard.connolly@tudublin.ie.

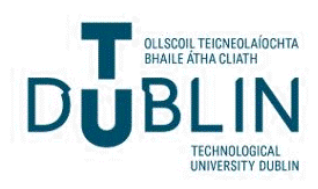




\section{Authors}

James Loughman; Eoin Duggan; Orna Donoghue,; Rose Anne Kenny; Hilary Cronin; and Ciarán Finucane

This article is available at ARROW@TU Dublin: https://arrow.tudublin.ie/otpomart/62 


\title{
Time to Refocus Assessment of Vision in Older Adults? Contrast Sensitivity but Not Visual Acuity Is Associated With Gait in Older Adults
}

\section{Eoin Duggan, ${ }^{1}$ Orna Donoghue, ${ }^{1}$ Rose Anne Kenny, ${ }^{1}$ Hilary Cronin, ${ }^{1}$ James Loughman, ${ }^{3,4}$ and Ciarán Finucane ${ }^{2}$}

'The Irish Longitudinal Study on Ageing (TILDA), Department of Medical Gerontology, Trinity College Dublin, Ireland. ${ }^{2}$ Department of Medical Physics and Bioengineering, Mercer's Institute for Successful Ageing, St. James's Hospital, Dublin, Ireland. ${ }^{3}$ Department of Optometry, Dublin Institute of Technology, Ireland. ${ }^{4}$ African Vision Research Institute, University of KwaZulu Natal, Durban, South Africa.

Address correspondence to Eoin Duggan, BE MB BCh BAO, The Irish Longitudinal Study on Ageing, Lincoln Gate, Trinity College Dublin, Dublin 2, Ireland. E-mail: eoin.duggan@ucdconnect.ie

Received June 17, 2016; Editorial Decision Date January 18, 2017

Decision Editor: Stephen Kritchevsky, PhD

\begin{abstract}
Background: The relationship between measures of visual function and gait related risk factors for falls is unclear. In this study, we examine the relationship between visual function (visual acuity [VA] and contrast sensitivity [CS] at multiple spatial frequencies) and quantitative spatiotemporal gait, using a large, nationally representative sample of community dwelling older adults.

Methods: Participants aged 50 and over were recruited as part of The Irish Longitudinal Study on Ageing (TILDA). VA was measured with the LogMAR chart according to the Early Treatment of Diabetic Retinopathy Study protocol. CS was measured at five spatial frequencies ranging 1.5 to 18 cycles per degree (cpd) using the Functional Acuity Contrast Test. Gait speed, cadence, and stride length were measured using the GAITRite system. Multivariate analysis examined associations between gait and visual performance parameters adjusting for socioeconomic, physical, cognitive, and mental health covariates.

Results: Data from 4,678 participants were analyzed (age $61.7 \pm 8.3$ years, $54.1 \%$ woman). Poorer CS at $1.5 \mathrm{cpd}$ and $3.0 \mathrm{cpd}$ (low spatial frequency) was independently associated with decreased stride length (CS at $1.5 \mathrm{cpd}: \beta=.031 ; p=.001$ and CS at $3.0 \mathrm{cpd}$ : $\beta=.020 ; p=.001$ ) but not cadence or gait speed. There was no evidence of an association between VA and any of the gait variables considered $(p>.05)$.

Conclusion: Reduced CS, at low spatial frequencies, is independently associated with shorter stride length, while VA is not associated with any gait measures. This evidence suggests that it may be necessary to consider refocus of the assessment of vision to include the most appropriate measures.
\end{abstract}

Keywords: Contrast sensitivity—Visual acuity—Falls

Thirty percent of older adults fall each year $(1,2)$. The consequences of falls are many and include injury, increased rates of hospitalization, fear of falling, mortality, and early admission to long-term care (3). Falls are associated with a significant economic burden with the annual cost of falls in the United States estimated to be $\$ 19.2$ billion (4). Elucidating mechanisms and identifying novel biomarkers of falls risk is thus paramount in older adults.

Gait impairments are one of the primary risk factors for falls in older adults with decreased gait speed and increased gait variability amongst a wide range of important features (2). Deterioration in visual performance is an accepted consequence of senescence (5), and is associated with increased falls rates $(6,7)$. There are a broad range of measures of visual performance including visual acuity (VA) and contrast sensitivity (CS). Optimization of VA has been identified as an important intervention in the American Geriatrics Society and British Geriatrics Society guidelines for the prevention of falls in the community (8). However, the relationship between measures of visual function and gait related risk factors for falls is less clear.

Although it is generally accepted in practice that vision influences gait patterns, the results from the small number of research 
studies addressing this question are conflicting. Some studies report no independent association between VA and common gait measures, that is, gait speed, cadence, and stride length (9-12). However, one large study ( $n=5,143)$ of older adults (age $>70$ years) notes that severe impairment in VA, after adjusting for age and gender, is associated with an inability to complete an 8-foot walk test (13). Another $(n=782)$ indicates, after adjusting for age, gender, previous stroke and diabetes, a significant association between failure on the Buck Center Walking Test (14) and reduced VA. Both these studies however, use gait measures which contain additional components of kinematic performance, for example, turning or physical endurance. Poorer CS, as measured using the Pelli-Robson test, has been independently associated with slower gait speed, shorter stride length, wider step width, increased double support time (10) and failure on the Buck Center Walking Test (14).

These studies have a number of limitations. Firstly, a broad range of gait, mobility and CS assessment methodologies and measures have been used, making comparison across studies difficult (9-15). In most cases, CS was measured at one spatial frequency with the PelliRobson $(9,12,14)$ or Melbourne Edge Test $(10,11,15)$, thereby preventing full characterization of the relationship between CS and gait parameters and its dependence on spatial frequency. Furthermore, previous models adjusted for a narrow range of potential confounders (9-15), with two studies focusing on selected populations, that is, age-related macular degeneration (10) and older women (11) and are therefore less generalizable to a broader population.

In this study, we examine the relationship between visual function (VA and CS at multiple spatial frequencies) and quantitative spatiotemporal gait parameters using a large, nationally representative sample of well-characterized, cognitively intact community dwelling older adults.

\section{Methods}

\section{Participants}

The Irish Longitudinal Study on Ageing (TILDA) is a large, nationally representative study of community dwelling adults aged 50 years and over, resident in Ireland. A stratified, clustered sample of 8,175 individuals was recruited using the RANSAM sampling framework (16), the details of which have been outlined previously (17). Ethical approval was provided by the Faculty of Health Sciences Research Ethics Committee at Trinity College Dublin. All participants provided written informed consent and the study adhered to the Declaration of Helsinki. The data presented here are based on wave 1 of the study which was undertaken between October 2009 and July 2011.

Social interviewers visited participants in their own homes where they completed a computer-assisted personal interview which addressed questions on socioeconomic, physical, cognitive and mental health factors. Participants were also invited to attend a dedicated health centre for a research nurse led health assessment (18).

Inclusion criteria included participation in the health centre assessment, completion of gait and vision assessments, a MiniMental State Examination score $\geq 18$ and no history of Parkinson's disease.

\section{Assessment of Vision}

VA was measured according to the Early Treatment of Diabetic Retinopathy Study (ETDRS) protocol using a LogMAR chart (19). Test results for the better eye were expressed in logarithmic units ranging from $1(20 / 200)$ to $-0.3(20 / 10)$, with lower values indicative of better vision.

CS was measured under mesopic conditions using the Functional Acuity Contrast Test (F.A.C.T.) incorporated in the Functional Vision Analyzer (Stereo Optical Co., Inc., Chicago, IL). The Functional Vision Analyzer is internally illuminated and as such is not influenced by varying light levels in examination rooms. The F.A.C.T. developed by Ginsberg (20) uses sinusoidal wave gratings to test CS at five different spatial frequencies: $1.5,3,6,12$, and 18 cycles per degree (cpd), corresponding to low (1 and $3 \mathrm{cpd}$ ), mid (6 cpd), and high (12 and $18 \mathrm{cpd}$ ) spatial frequencies. CS was measured monocularly for the eye with better VA resulting in a CS score (ranging 0-9) at each spatial frequency.

\section{Assessment of Gait}

Gait assessment was performed using a 4.9 m GAITRite electronic walkway (CIR Systems Inc., Sparta, NJ) which automatically records participant footfalls and calculates spatiotemporal gait parameters. Participants were asked to walk at a normal pace, starting $2.5 \mathrm{~m}$ before and stopping $2.0 \mathrm{~m}$ after the walkway to control for acceleration and deceleration effects. Each participant completed two walks and the data from both were combined.

Three gait variables were analyzed: gait speed, cadence, and stride length. Gait speed $(\mathrm{cm} / \mathrm{s})$ is the average speed over the two walks. Cadence is the average number of footfalls per minute. Stride length $(\mathrm{cm})$ is the distance between sequential initial contacts with the ground for the same limb. The average stride length of the right and left lower limbs was used in this study. These three variables are related according to the equation: Gait speed $=$ stride length $\times$ cadence/ 120 .

\section{Covariates}

During the computer-assisted personal interview, participants reported their level of educational attainment, a doctor's diagnosis of the following chronic conditions: heart attack or heart failure or angina, hypertension, high cholesterol, stroke, diabetes, lung disease, asthma, arthritis, osteoporosis, cancer, peptic ulcer disease, and hip fracture. This was categorized as $0,1,2$, and 3 or more chronic conditions. The participants' regular medications were recorded and coded according to the Anatomical Therapeutic Chemical (ATC) Classification codes. Depressive symptoms during the past week were assessed using the eight-item Centre for Epidemiological Studies Depression scale (CES-D) (21). Participants were also asked whether they had fallen in the past year and if so, on how many occasions. The responses were categorized into 1,2, and 3 or more falls. Participants also indicated if they felt unsteady when they stood or walked, whether they had ever been diagnosed with cataracts, glaucoma or age-related macular degeneration and whether they had undergone cataract surgery in the past.

Height $(\mathrm{cm})$ and weight $(\mathrm{kg})$ were measured using a SECA height rod and weighing scales respectively. Global cognition was assessed using the Mini-Mental State Examination (22). Executive function was assessed using the difference in time taken to complete trail 1 and trail 2 tasks in the color trails test (23). Processing speed was assessed using a choice reaction time (CRT) test. In this test, participants held a button down, released it in response to an on-screen stimulus and pressed the appropriate target button. The mean time from 100 appearances of the stimulus to pressing the correct button is the total response time. Maximum grip strength $(\mathrm{kg})$ was measured as the highest score from two tests on each hand using a Baseline hydraulic hand dynamometer (Fabrication Enterprises, 
White Plains, NY). Participants wore distance corrective lenses if required during vision and gait testing.

\section{Statistical Analysis}

Demographics of those included in the study were examined using Chi-squared test statistics and independent $t$ tests.

Pearson's and Spearman's rank correlations were used to examine the univariate relationships between VA, CS, and the gait variables (speed, cadence, and stride length). Multivariate linear regression models were constructed to investigate the associations between VA, CS and the three dependent gait variables (speed, cadence, and stride length). For each dependent variable, two models were created. Model 1 adjusted for age, gender, education, height, and weight. Model 2 also adjusted for history of falls, number of medications, number of chronic conditions, depressive symptoms, color trail time difference, Mini-Mental State Examination, total response time, grip strength, history of cataracts (treated and untreated), history of glaucoma, and age-related macular degeneration. All data were analyzed using Stata Version 12 (StataCorp, College Station, TX). All regressions were adjusted to account for the clustered sampling design and a False Discovery Rate procedure applied to correct $p$ values for multiple testing. Sensitivity analyses were also performed to examine the effects of controlling for age $^{2}$, age-gender interactions and averaging CS values across $1.5-18 \mathrm{cpd}$ on the regression results.

\section{Results}

\section{Characteristics of the Study Sample}

Of the 5,028 participants (aged $\geq 50$ years) who attended the TILDA health assessment, 4,678 were included in the study. Reasons for exclusion were a history of Parkinson's disease $(n=16)$, non-completion of gait assessment $(n=75)$, non-completion of VA assessment $(n=20)$, non-completion of the CS test $(n=228)$, and moderate to severe cognitive impairment, defined as an Mini-Mental State Examination score less than $18(n=11)$. The mean age of the sample was $61.7 \pm 8.3$ years, $54.1 \%$ of whom were woman. The characteristics of the sample are outlined in Table 1.

\section{Univariate Analysis of Vision and Gait}

VA was inversely correlated with gait speed $(r=-.14 ; p<.001)$ and stride length $(r=-.18 ; p<.001)$. As lower values in LogMAR correspond to better VA, this indicates that better VA is correlated with better gait performance (see Table 2 and Supplementary Figure A1.1). At all spatial frequencies, CS was correlated with gait speed $(r=.08$ to $.16, p<.001)$ and stride length $(r=.12$ to $.22, p<.001)$. VA and CS were not correlated significantly with cadence.

\section{Multivariate Analysis of Vision and Gait}

Visual acuity

There was no evidence of an association between VA and any gait variable in either model 1 or model 2 (see Table 3 and Supplementary Tables A1.1-A1.3).

\section{Contrast sensitivity}

Figure 1A shows the regression coefficients from the models examining associations between CS at each of these five individual spatial frequencies and gait speed. Higher CS at low spatial frequencies was associated with faster gait speed in model 1 (CS at $1.5 \mathrm{cpd}$, $\beta=.053 ; p<.001$; CS at $3 \mathrm{cpd}, \beta=.033 ; p<.001)$. After adjustment
Table 1. Characteristics of the Participants $(n=4,678)$

\begin{tabular}{|c|c|}
\hline Characteristics & Mean $(S D)$ or Median $(\mathrm{IQR})$ or $\%(N)$ \\
\hline Age (y) & $61.7 S D(8.3)$ \\
\hline Sex (\% woman) & $54.1(2,529)$ \\
\hline $\begin{array}{l}\text { Primary or no formal education } \\
(\%)\end{array}$ & $21.3(994)$ \\
\hline Weight $(\mathrm{kg})$ & $79.2 S D(16.2)$ \\
\hline Height (cm) & 166.3SD (9.1) \\
\hline \multicolumn{2}{|l|}{ Medical history } \\
\hline Chronic conditions $\geq 2$ (\%) & $45.3(2,119)$ \\
\hline Falls $(\%)$-one or more & $19.7(920)$ \\
\hline Glaucoma (\%) & $1.93(90)$ \\
\hline $\operatorname{AMD}(\%)$ & $1.48(69)$ \\
\hline Cataracts $(\%)$ & $8.3(386)$ \\
\hline Anti-depressants & $5.7(265)$ \\
\hline Alpha blockers & $1.4(66)$ \\
\hline Beta blockers & $12.1(566)$ \\
\hline Calcium channel blockers & $8.3(389)$ \\
\hline Diuretics & $6(281)$ \\
\hline ACE/ARB & $22(1,029)$ \\
\hline Psychotropics & $5.3(246)$ \\
\hline \multicolumn{2}{|l|}{ Cognitive and mental health } \\
\hline MMSE (range 1-30) & $28.7 S D(1.6)$ \\
\hline CES-D & $4.4 S D(4.0)$ \\
\hline CRT (ms) & $806 S D(260.7)$ \\
\hline Color trail time $(\mathrm{s})$ & $53.7 S D(26.7)$ \\
\hline Grip strength $(\mathrm{kg})$ & $27.5 S D(9.8)$ \\
\hline \multicolumn{2}{|l|}{ Gait function } \\
\hline Gait speed $(\mathrm{cm} / \mathrm{s})$ & 136.1 SD (20.4) \\
\hline Cadence (steps/min) & 115.6 SD (10.4) \\
\hline Stride Length $(\mathrm{cm})$ & 141.6 SD (17.6) \\
\hline \multicolumn{2}{|l|}{ Visual function } \\
\hline Corrective lenses & $37.9(1,772)$ \\
\hline Visual acuity (logMAR) & $0.1 S D(0.2)$ \\
\hline CS $1.5 \mathrm{cpd}$ & 36.0 IQR (11) \\
\hline CS $3 \mathrm{cpd}$ & $57 \operatorname{IQR}(23)$ \\
\hline CS 6 cpd & 33.0 IQR (29) \\
\hline CS $12 \mathrm{cpd}$ & 0 IQR (15) \\
\hline CS $18 \mathrm{cpd}$ & 0 IQR (0) \\
\hline
\end{tabular}

Note: $\mathrm{ACE} / \mathrm{ARB}=$ angiotensin converting enzyme/angiotensin receptor blockers; $\mathrm{AMD}=$ age-related macular degeneration; CES-D = Centre for Epidemiological Studies Depression scale; CRT $=$ Choice reaction time (total time); $C S=$ contrast sensitivity cpd $=$ cycles per degree; MMSE = Mini-Mental State Exam; IQR = interquartile range. Corrective Lenses = Wore corrective lenses as required.

(and correction for multiple testing), there was no evidence of an association remaining in model 2 (Table 3).

Figure $1 \mathrm{~B}$ indicates that poorer CS was associated with shorter stride length at lower spatial frequencies in model 1 (1.5 cpd $[\beta=.051 ; p=.001] ; 3 \mathrm{cpd}[\beta=.036 ; p<.001])$ with evidence of a trend at mid frequencies $(6 \mathrm{cpd}[\beta=.024 ; p=.002])$. In model 2 , $\mathrm{CS}$ at $1.5 \mathrm{cpd}(\beta=.031 ; p=.001)$ and $3 \mathrm{cpd}(\beta=.029 ; p=.001)$ remained significant after correcting for multiple testing (Table 3 ).

There was no clear evidence of an association between CS and cadence in either model 1 or model 2 (see Figure 1C and Table 3).

\section{Discussion}

Results from this study suggest that reductions in CS but not VA are independently associated with poorer gait performance.

Our findings support previous studies reporting that better CS is associated with increased stride length $(10,11,15)$. However, ours is 
Table 2. Univariate Correlations Between Visual Function (VA and CS) and Gait (Gait Speed, Cadence and Stride Length).

\begin{tabular}{|c|c|c|c|c|c|c|}
\hline & VA & CS $1.5 \mathrm{cpd}$ & CS $3 \mathrm{cpd}$ & CS $6 \mathrm{cpd}$ & CS $12 \mathrm{cpd}$ & CS $18 \mathrm{cpd}$ \\
\hline Gait speed & $-0.14 * * *$ & $0.12 * * *$ & $0.16^{* * * *}$ & $0.13 * * *$ & $0.13^{* * *}$ & $0.08 * * *$ \\
\hline Cadence & 0.01 & -0.02 & $-0.03 *$ & -0.02 & -0.02 & -0.03 \\
\hline Stride length & $-0.18 * * *$ & $0.16^{* * *}$ & $0.22 * * *$ & $0.18 * * *$ & $0.17 * * *$ & $0.12 * * *$ \\
\hline
\end{tabular}

Note: $\mathrm{cpd}=$ cycles per degree; $\mathrm{CS}=$ contrast sensitivity; $\mathrm{VA}=$ Visual acuity.

* $p \leq .05 ; * * \leq .01 ; * * p \leq .001$.

Table 3. Multivariate Model Estimates of the Association Between VA, CS, and Gait Function (Gait Speed, Cadence, Stride Length)

\begin{tabular}{|c|c|c|c|}
\hline & Gait Speed $(\mathrm{cm} / \mathrm{s})$ & Cadence (footfalls per min) & Stride Length $(\mathrm{cm})$ \\
\hline & $\beta(95 \% \mathrm{CI})$ & $\beta(95 \% \mathrm{CI})$ & $\beta(95 \% \mathrm{CI})$ \\
\hline \multicolumn{4}{|l|}{ VA } \\
\hline Model 1 & $-1.53(-4.71,1.65)$ & $0.29(-1.17,1.76)$ & $-2.14(-4.50,0.22)$ \\
\hline Model 2 & $-1.32(-4.45,1.82)$ & $-0.025(-1.55,1.50)$ & $-1.43(-3.72,0.87)$ \\
\hline \multicolumn{4}{|c|}{ CS A (1.5 cpd) } \\
\hline Model 1 & $0.053(0.025,0.08) * * *$ & $0.0053(-0.0083,0.019)$ & $0.051(0.031,0.071) * * *$ \\
\hline Model 2 & $0.029(0.0029,0.056)^{*}$ & $-0.00018(-0.013,0.014)$ & $0.031(0.013,0.049) * * *$ \\
\hline \multicolumn{4}{|c|}{ CS B (3 cpd) } \\
\hline Model 1 & $0.033(0.017,0.049)^{* * * *}$ & $-0.00016(-0.0083,0.008)$ & $0.036(0.024,0.048)^{* * *}$ \\
\hline Model 2 & $0.015(-0.001,0.031)$ & $-0.003(-0.012,0.004)$ & $0.021(0.009,0.032)^{* * *}$ \\
\hline \multicolumn{4}{|c|}{ CS C (6 cpd) } \\
\hline Model 1 & $0.011(-0.0087,0.031)$ & $-0.0082(-0.018,0.0016)$ & $0.024(0.009,0.038) * *$ \\
\hline Model 2 & $-0.0058(-0.025,0.014)$ & $-0.011(-0.021,-0.001)^{*}$ & $0.008(-0.005,0.022)$ \\
\hline \multicolumn{4}{|c|}{ CS D (12 cpd) } \\
\hline Model 1 & $0.0075(-0.046,0.061)$ & $-0.023(-0.047,0.00035)$ & $0.039(0.0007,0.077)^{*}$ \\
\hline Model 2 & $-0.014(-0.064,0.037)$ & $-0.024(-0.048,-0.00068) *$ & $0.016(-0.018,0.051)$ \\
\hline \multicolumn{4}{|c|}{ CS E (18 cpd) } \\
\hline Model 1 & $0.047(-0.14,0.24)$ & $-0.061(-0.15,0.025)$ & $0.12(-0.017,0.26)$ \\
\hline Model 2 & $-0.024(-0.209,0.16)$ & $-0.07(-0.15,0.014)$ & $0.056(-0.077,0.19)$ \\
\hline
\end{tabular}

Note: A-E = visual targets of increasing spatial frequency and varying CS; $\mathrm{CI}=$ confidence interval; $\mathrm{cpd}$ = cycles per degree; $\mathrm{CS}=$ contrast sensitivity; $\mathrm{MMSE}=\mathrm{Mi}-$ ni-Mental State Exam; VA = visual acuity. Model 1 = multivariate model adjusted for age, gender, education, height and weight; Model $2=$ multivariate model adjusted for age, gender, education, height, weight, history of falls, medications including: $\alpha$-, $\beta$ - \& calcium channel blockers, diuretics, angiotensin-convertingenzyme inhibitors (ACEI), angiotensin receptor blockers (ARB), antidepressants and psychotropics, self-reported unsteadiness, corrective lens wearing, number of chronic diseases, depressive symptoms, color trail time, MMSE, total response time from the Choice Reaction Time (CRT) test, grip strength, history of cataracts, treated and untreated, history of glaucoma and age-related macular degeneration (AMD).

* $p \leq .05 ; * * p \leq .01 ; * * p \leq .001$.

the first study to measure CS at multiple spatial frequencies across the low, mid, and high range. This is a more appropriate method of characterizing CS and allows us to gain further insight into this relationship. Results suggest that the relationship between CS and gait is spatial frequency dependent, with poorer CS at lower spatial frequencies associated with shorter stride length. Our regression results would suggest that these results have a small effect size which translates into a $2.65 \mathrm{~cm}$ difference in stride length between the 5 th and 95th percentiles of CS. Although a small effect size, when combined with other falls risk factors, this magnitude of difference could affect an individual's ability to avoid tripping over an obstacle.

The association between CS (at lower spatial frequencies) and stride length is intuitively satisfying and provides a possible mechanistic link between vision, gait, and future falls. Previous research has shown that low-to-mid spatial frequencies play a role in object detection (24,25), and those with poorer CS may shorten their stride length to accommodate for being unsure of their surroundings. Shorter stride lengths coupled with a higher cadence have been observed in older fallers (26) while shortened stride length and reduced speed is associated with increased falls risk in older adults (27) and hospitalized patients (28). Thus by contributing to gait impairments and impaired object detection, poor CS may contribute to object avoidance (29) and increased falls risk. In considering the clinical application of these results as a screening tool it may be more convenient to test for low spatial frequency only, that is, using only the low-frequency components of the F.A.C.T. (20).

Finally, our results examining VA supports previous research reporting significant univariate (but no multivariate) correlations between VA and gait variables $(9,11,12)$. Owsley and colleagues (25) note that VA did not contribute to the detection of real world objects while Hassan and colleagues (30) reported no evidence of an association between VA and mobility over a complicated obstacle course. Our results after adjustment suggest that high contrast, detailed vision (as measured by VA) may not be essential to basic straight line walking. This is in agreement with previous studies that have indicated that CS is a better measure for fall risk than VA $(6,31,32)$. Despite this, assessment of VA is included in the falls screening and assessment guidelines (8). The evidence provided here suggests that the inclusion of VA alone requires re-evaluation as a more comprehensive visual assessment may be more appropriate.

Results of additional sensitivity analyses would suggest that the regression estimates are robust after adjusting for $\mathrm{age}^{2}$ and 

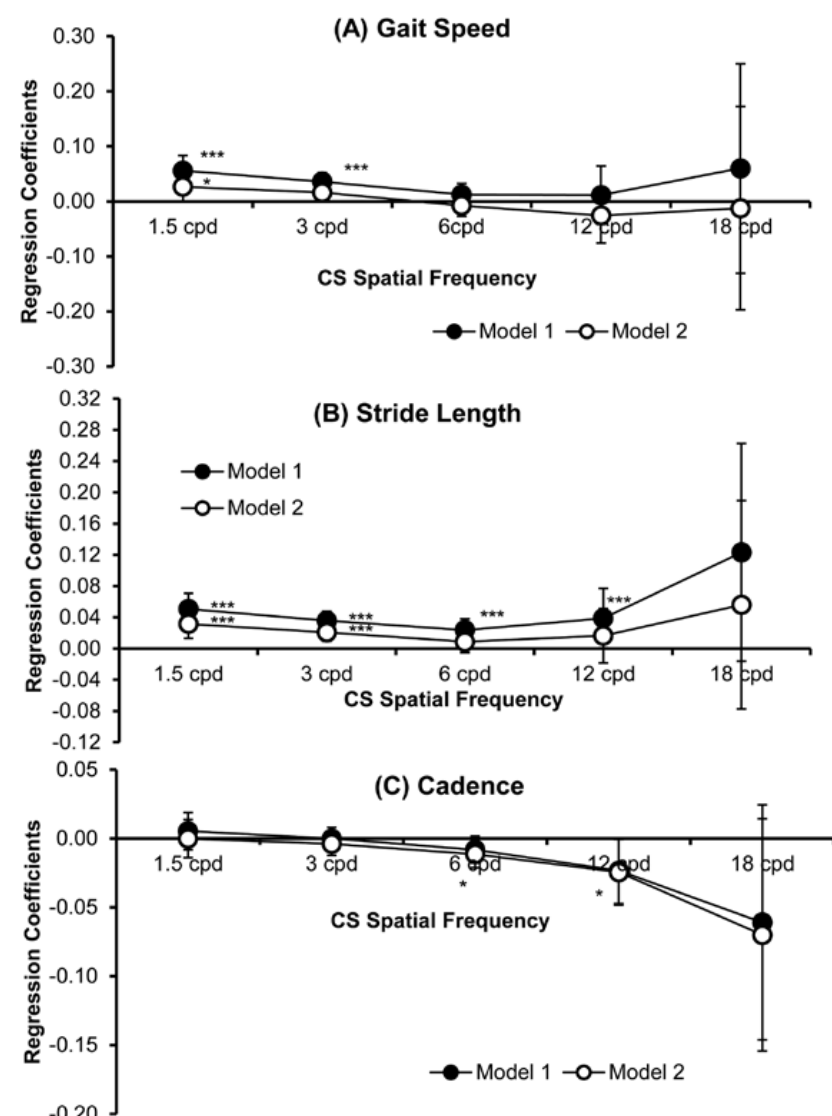

Figure 1. Linear regression model coefficients between gait parameters (A. gait speed; B. stride length; C. cadence) and contrast sensitivity (CS) at five spatial frequencies. Model 1 adjusted for: age, gender, education, height and weight. Model 2 adjusted for age, gender, education, height, weight, history of falls, medications including: $\alpha-, \beta$ - \& calcium channel blockers, diuretics, angiotensin-converting-enzyme inhibitors (ACEI), angiotensin receptor blockers (ARB), antidepressants and psychotropics, self-reported unsteadiness, corrective lens wearing, number of chronic diseases, depressive symptoms, color trail time, Mini-Mental State Exam (MMSE), total response time from the Choice Reaction Time (CRT) test, grip strength, history of cataracts, treated and untreated, history of glaucoma, and age related macular degeneration (AMD). ${ }^{*} p \leq .05 ;{ }^{* *} p \leq .01 ;{ }^{* *} p \leq .001$.

age-sex interactions which are known to influence gait. Furthermore, although we applied a false discovery rate approach to correct for multiple testing effects, we also tested the effect of using the average CS value for each participant in a sensitivity analysis, which has methodological advantages of increasing the precision of our estimates, normalizing the model residuals, and minimizing multiple testing effects. Again our results were consistent with CS associated with stride length.

This study has a number of strengths including the measurement of CS at individual spatial frequencies. Secondly it utilizes a large representative sample, coupled with a comprehensive health, socioeconomic profile of each participant enabling statistical inferences to be made which are more generalizable to the broader older community dwelling adult population. There are, however, a number of limitations to the study. It is cross-sectional limiting any conclusions regarding causation. Analysis was limited to those who attended a health center assessment. This cohort is relatively young (mean age 62 years), healthy (gait speed and VA mostly within healthy ranges) and therefore is less representative of frailer adults. The gait assessment task used in this study reflects straight line walking undertaken in conditions of high luminance, contrast and is free from hazards. The role of vision in this context is likely less critical than under more challenging conditions comprising obstacle avoidance and lower lighting which may account for small effect size detected here $(12,32,33)$. In light of these results, a more comprehensive battery of visual tests should be considered including stereoacuity and visual field size (34). However, CS is most reflective of real world vision as it includes object of varying size and contrast unlike VA or stereoacuity. Although important fall risk covariates, lower limb strength and standing balance, were not measured directly, we controlled for grip strength which is known to correlate well with lower limb strength $(35,36)$. During sensitivity analysis we adjusted for self-reported steadiness as a surrogate for standing balance. This did not alter associations between CS and gait.

\section{Conclusion}

Reduced CS, particularly at low spatial frequencies, is independently associated with shorter stride length, while VA is not associated with gait performance. VA is currently included in the American Geriatrics Society/ British Geriatrics Society guidelines for screening and assessment of falls in community dwelling adults. The evidence provided here would suggest that future studies should examine longitudinally, or in a randomized controlled manner, the associations between CS and other measures of visual function with gait especially in the context of falls. This may ultimately lead to a refocus of the clinical exam to include assessment of the most appropriate measures of visual function.

\section{Supplementary Material}

Supplementary data are available at The Journals of Gerontology, Series A: Biological Sciences and Medical Sciences online.

\section{Funding}

This work was supported by The Department of Health of the Irish Government, The Atlantic Philanthropies, Irish Life Assurance PLC, and The Health Research Board, Ireland.

\section{Acknowledgments}

The authors would like to thank the participants and staff of The Irish Longitudinal Study on Ageing.

\section{Conflict of Interest}

The authors declare no conflicts of interest.

\section{References}

1. Verghese J, LeValley A, Hall CB, et al. Epidemiology of gait disorders in community-residing older adults. J Am Geriatr Soc. 2006;54:255-261. doi:10.1111/j.1532-5415.2005.00580.x

2. Verghese J, Holtzer R, Lipton RB, Wang C. Quantitative gait markers and incident fall risk in older adults. J Gerontol A Biol Sci Med Sci. 2009;64:896-901. doi:10.1093/gerona/glp033.

3. Tinetti ME, Williams CS. Falls, injuries due to falls, and the risk of admission to a nursing home. N Engl J Med.1997;337:1279-1284. doi:10.1056/ NEJM199710303371806

4. Stevens JA, Corso PS, Finkelstein EA, et al. The costs of fatal and nonfatal falls among older adults. Inj Prev. 2006;12:290-295. doi:10.1136/ ip. 2005.011015 
5. Owsley C. Aging and vision. Vision Res. 2011;51:1610-1622. doi:10.1016/j.visres.2010.10.020

6. de Boer MR, Pluijm SM, Lips P, et al. Different aspects of visual impairment as risk factors for falls and fractures in older men and women.J Bone Miner Res. 2004;19:1539-1547. doi:10.1359/JBMR.040504.

7. Klein BE, Moss SE, Klein R, et al. Associations of visual function with physical outcomes and limitations 5 years later in an older population: the Beaver Dam eye study. Ophthalmology. 2003;110:644-650. doi:10.1016/ S0161-6420(02)01935-8

8. Panel on Prevention of Falls in Older Persons, American Geriatrics Society and British Geriatrics Society. Summary of the Updated American Geriatrics Society/British Geriatrics Society clinical practice guideline for prevention of falls in older persons. J Am Geriatr Soc. 2011;59:148-157. doi:10.1111/j.1532-5415.2010.03234.x

9. Klein BE, Klein R, Lee KE, et al. Performance-based and self-assessed measures of visual function as related to history of falls, hip fractures, and measured gait time. The Beaver Dam Eye Study. Ophthalmology. 1998;105:160-164. doi:10.1016/S0161-6420(98)91911-X

10. Wood JM, Lacherez PF, Black AA, et al. Postural stability and gait among older adults with age-related maculopathy. Invest Ophthalmol Vis Sci. 2009;50:482-487. doi:10.1167/iovs.08-1942

11. Lord SR, Lloyd DG, Li SK. Sensori-motor function, gait patterns and falls in community-dwelling women. Age Ageing. 1996;25:292-299. doi:10.1093/ageing/25.4.292

12. Patel I, Turano KA, Broman AT, et al. Measures of visual function and percentage of preferred walking speed in older adults: the Salisbury Eye Evaluation Project. Invest Ophthalmol Vis Sci. 2006;47:65-71. doi:10.1167/iovs.05-0582

13. Salive ME, Guralnik J, Glynn RJ, et al. Association of visual impairment with mobility and physical function. J Am Geriatr Soc. 1994;42:287-292. doi:10.1111/j.1532-5415.1994.tb01753.x

14. West CG, Gildengorin G, Haegerstrom-Portnoy G et al. Is vision function related to physical functional ability in older adults? J Am Geriatr Soc. 2002;50:136-145. doi:10.1046/j.1532-5415.2002.50019.x

15. Callisaya ML, Blizzard L, Schmidt MD, et al. A population-based study of sensorimotor factors affecting gait in older people. Age Ageing. 2009;38:290-295. doi:10.1093/ageing/afp017

16. Whelan BJ. RANSAM: A National Sampling Design for Ireland. Econ Soc Rev. 1979;10:169-174.

17. Kearney PM, Cronin H, O'Regan C, et al. Cohort profile: the Irish Longitudinal Study on Ageing. Int J Epidemiol. 2011;40:877-884. doi:10.1093/ije/dyr116.

18. Cronin H, O'Regan C, Finucane C, et al. Health and aging: development of the Irish Longitudinal Study on Ageing health assessment. J Am Geriatr Soc. 2013;61(suppl 2):S269-S278. doi:10.1111/jgs.12197

19. Early Treatment Diabetic Retinopathy Study Research Group. Early Treatment Diabetic Retinopathy Study design and baseline patient characteristics. ETDRS report number 7. Ophthalmology. 1991;98(5 Suppl):741-756. doi:10.1016/S0161-6420(13)38009-9
20. Ginsburg AP.A new contrast sensitivity vision test chart. Am J Optom Physiol Opt. 1984;61:403-407. doi:10.1097/00006324-198406000-00011

21. Radloff LS. The CES-D Scale: a self-report depression scale for research in the general population. Appl Psychol Meas. 1977;1:385-401. doi:10.1177/014662167700100306

22. Folstein MF, Folstein SE, McHugh PR. "Mini-mental state". A practical method for grading the cognitive state of patients for the clinician. $J$ Psychiatr Res. 1975;12:189-198. doi:10.1016/0022-3956(75)90026-6

23. D'Elia LF, Satz P, Lyons Uchiyama C, et al. Color Trails Test. Professional Manual. Odessa, FL: Psychological Assessment Resources, Inc: 1996.

24. Kuyk T, Elliott JL. Visual factors and mobility in persons with age-related macular degeneration. J Rehabil Res Dev. 1999;36:303-312.

25. Owsley C, Sloane ME. Contrast sensitivity, acuity, and the perception of 'real-world' targets. Br J Ophthalmol. 1987;71:791-796. doi:10.1136/ bjo.71.10.791

26. Barak Y, Wagenaar RC, Holt KG. Gait characteristics of elderly people with a history of falls: a dynamic approach. Phys Ther. 2006;86:15011510. doi:10.2522/ptj.20050387.

27. Callisaya ML, Blizzard L, McGinley JL, et al. Risk of falls in older people during fast-walking--the TASCOG study. Gait Posture. 2012;36:510515. doi:10.1016/j.gaitpost.2012.05.003

28. Guimaraes RM, Isaacs B. Characteristics of the gait in old people who fall. Int Rehabil Med. 1980;2:177-180. doi:10.3109/09638288009163984

29. Kuyk T, Elliott JL, Biehl J, et al. Environmental variables and mobility performance in adults with low vision. J Am Optom Assoc. 1996;67:403-409.

30. Hassan SE, Lovie-Kitchin JE, Woods RL. Vision and mobility performance of subjects with age-related macular degeneration. Optom Vis Sci. 2002;79:697-707. doi:10.1097/00006324-200211000-00007

31. Ivers RQ, Cumming RG, Mitchell P, et al. Visual impairment and falls in older adults: the Blue Mountains Eye Study. J Am Geriatr Soc. 1998;46:58-64. doi:10.1111/j.1532-5415.1998.tb01014.x

32. Menant JC, Smith S, Lord SR. Visual determinants of instability and falls. Aging Health. 2008;4:643-650. doi:10.2217/1745509X.4.6.643

33. Heasley K, Buckley JG, Scally A, Twigg P, Elliott DB. Falls in older people: effects of age and blurring vision on the dynamics of stepping. Invest Ophthalmol Vis Sci. 2005;46:3584-3588. doi:10.1167/ iovs.05-0059

34. Menant JC, St George RJ, Fitzpatrick RC, et al. Impaired depth perception and restricted pitch head movement increase obstacle contacts when dual-tasking in older people. J Gerontol A Biol Sci Med Sci. 2010;65:751-757. doi:10.1093/gerona/glq015

35. Bohannon RW, Magasi SR, Bubela DJ, et al. Grip and knee extension muscle strength reflect a common construct among adults. Muscle Nerve. 2012;46:555-558. doi:10.1002/mus.23350

36. Aadahl M, Beyer N, Linneberg A, et al. Grip strength and lower limb extension power in 19-72-year-old Danish men and women: the Health2006 study. BMJ Open. 2011;1:e000192. doi:10.1136/ bmjopen-2011-000192 